\title{
Service Assessment Planning for the Hunt Library Dataspace
}

Margaret Peak, Mia Partlow, Karen Ciccone, and Walt Gurley NC State University Libraries 


\section{Data \& Visualization Services Department}

We provide:

Consultations, workshops, and classroom instruction related to data science and visualization

\section{Areas:}

GIS, data cleaning, qualitative and quantitative analysis, visualization design, and more...

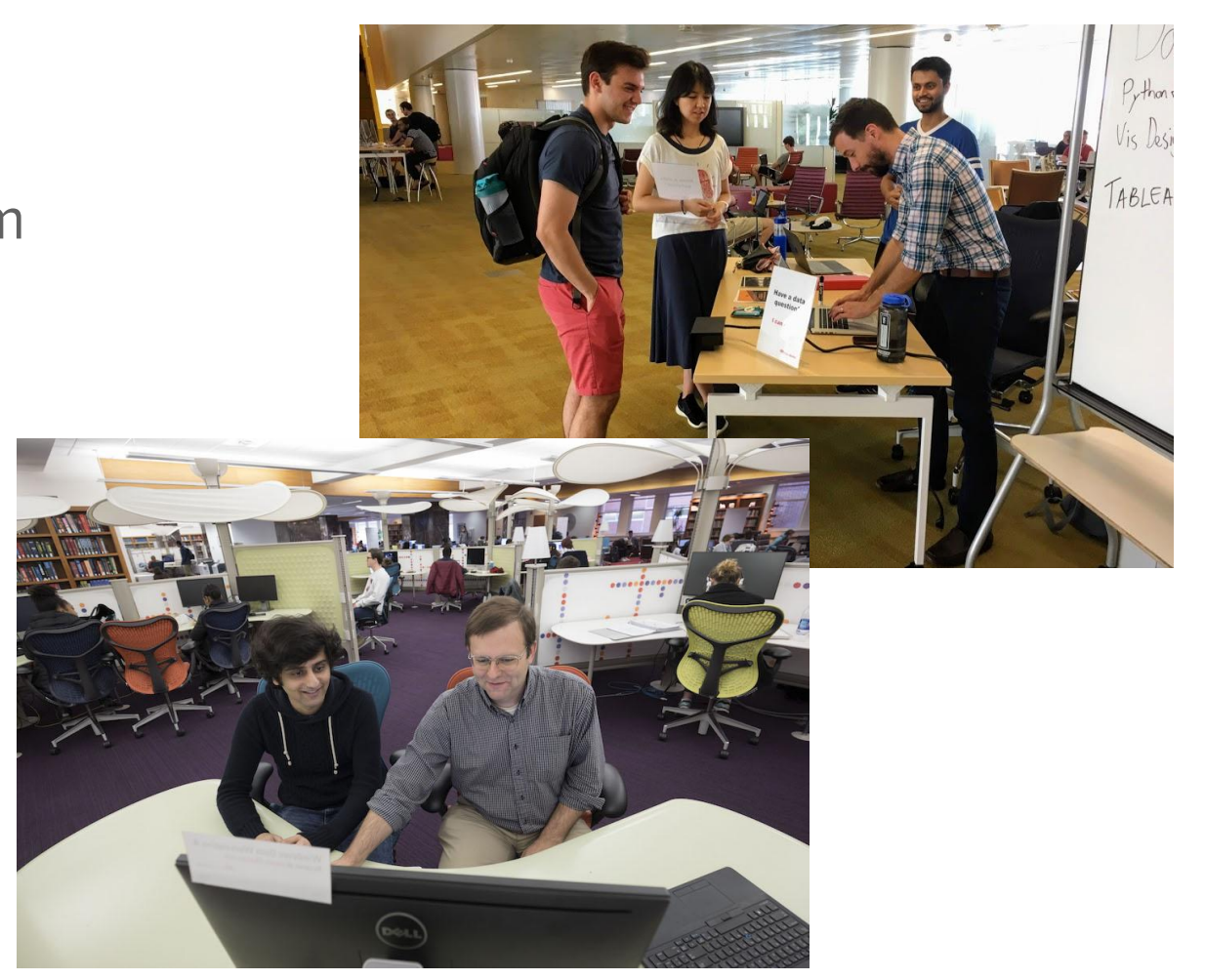




\section{Hunt Library Dataspace}

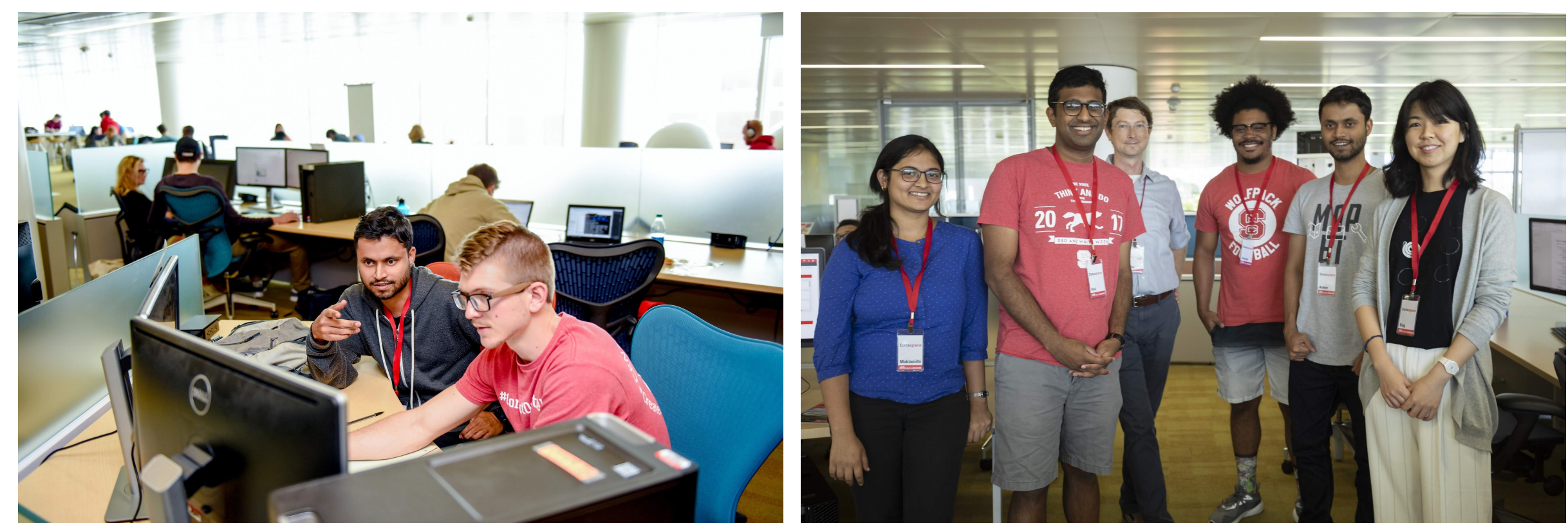




\section{"Why are you}

\section{opening a computer}

\section{lab in 2018?"?}

Provide computing power, software, and expertise so students can develop foundational skills in data science

Reach undergraduates and those who might not come to the libraries for data science support

\section{Our first year:}

8,311 total logins and 1,475 staff interactions in the Dataspace 


\section{Assessment Plan}

\section{Three Major Goals}

- To gauge how the use of the Dataspace aligned with the University and Libraries Strategic Plan

- To expose areas where we could improve services

- To evaluate how the space was used to inform the creation of a similar space in the D. H. Hill Library Renovation 


\section{Assessment Plan}

\section{Approach:}

- Start with each relevant strategic goal of University and Libraries

- Discuss what data would be needed to evaluate services related to each goal

- Set up the mechanisms and instruments needed to gather data prior to opening the space

- Pull together a lot of different data to tell the full story of these spaces 


\section{Assessment Story: Undergraduates}

NC State Strategic Priority: Enhance success of our students through educational innovation

Libraries Strategic Initiative: Provide high-impact educational experiences for undergraduates

Mechanisms for data gathering:

- LabStats for student logins

- Reservation system

- Student Information Systems linked to logins for College and Status

- Suma and Google Form data for consultation services 


\section{Dataspace Consultation Services}

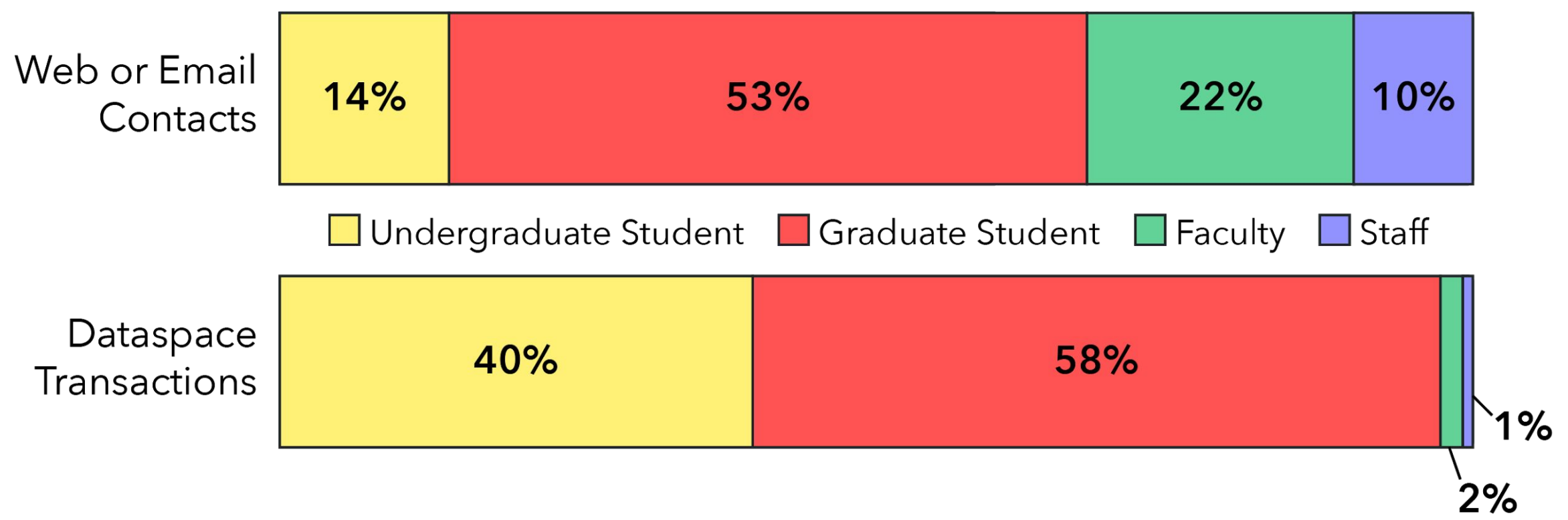




\section{Dataspace support - length of consultation}

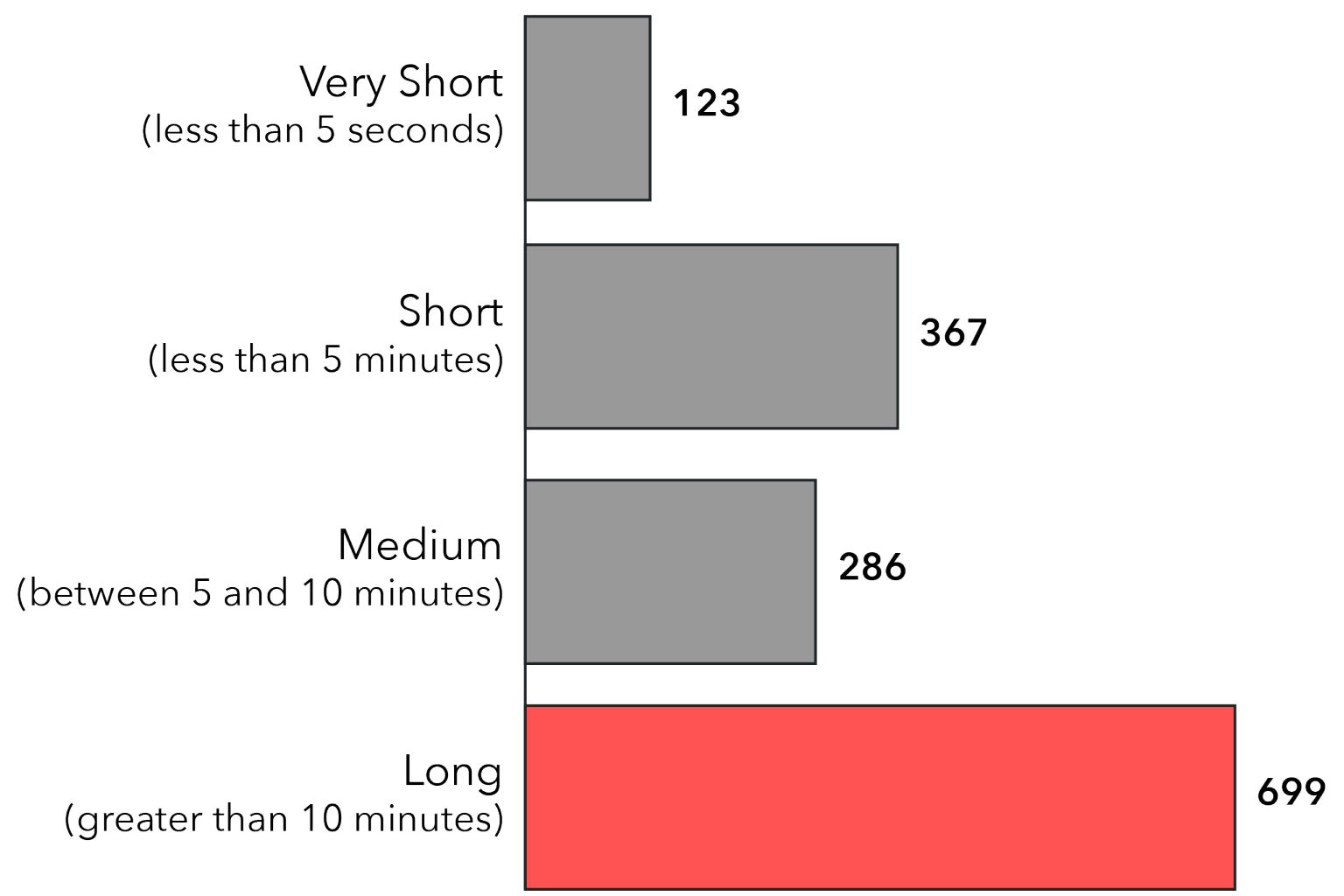




\section{Assessment Story: Reservations}

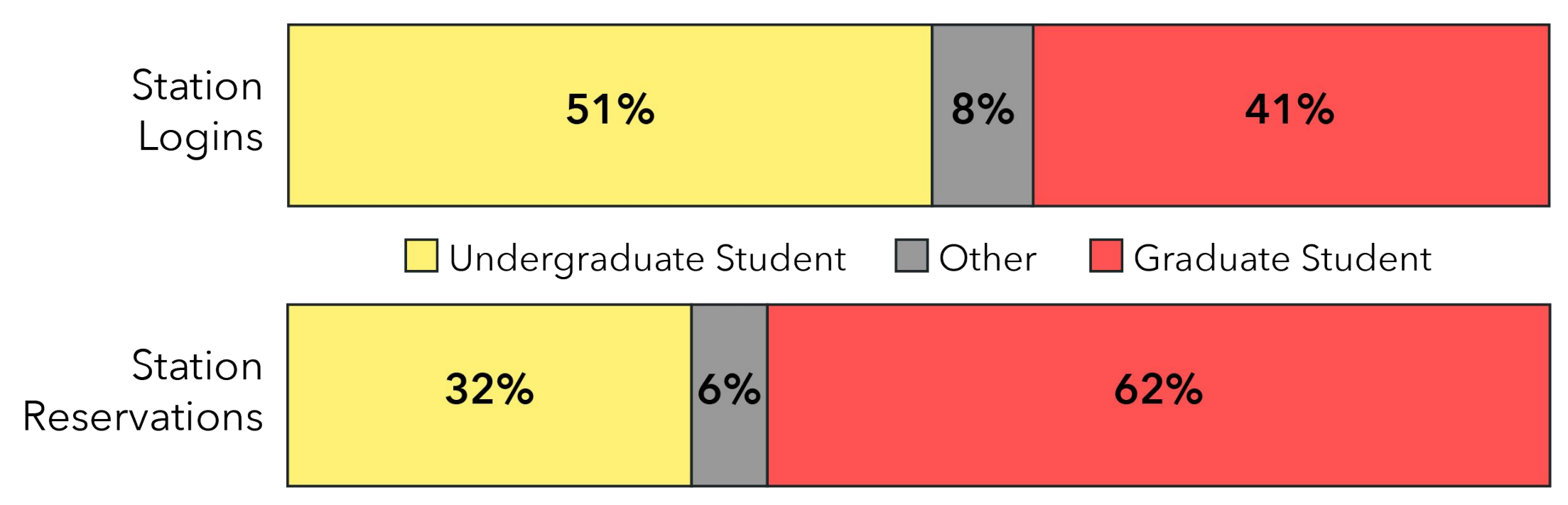




\section{Collecting Qualitative Data for Service Improvement}

\section{Transactional data only gives us part of the picture}

Surveyed students in Spring 2019 to find out how well we're meeting needs and what unmet needs exist

Identified areas for improvement:

Better signage and communication for reserved workstations

More group workspace and laptop stations

More Advanced PCs
Q5 - Does the Dataspace have the software you need?

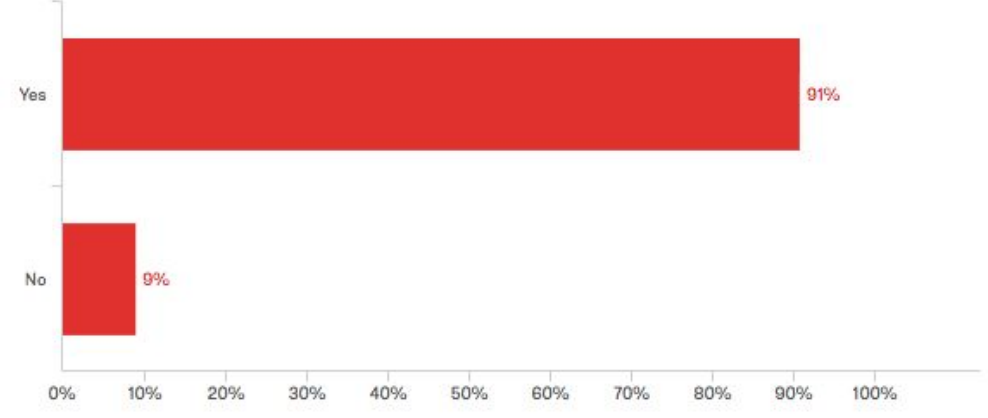




\section{Our experience}

Starting an assessment project from our strategic goals and initiatives led to meaningful outcomes

Pairing transactional data with qualitative data enabled us to answer tough questions about the user experience in our spaces

\section{Our takeaway:}

Don't focus on the measures that are easy to collect or the data that's available; focus on questions you're trying to answer and then think about what data you need. 


\section{Contact Us}

Margaret Peak, Director, Planning and Research mlpeak@ncsu.edu

Karen Ciccone, Head, Data \& Visualization Services kacollin@ncsu.edu

Walt Gurley, Data \& Visualization Librarian jwqurley@ncsu.edu

Mia Partlow, NCSU Libraries Fellow mia_partlow@ncsu.edu

Dataspace User Research Report:

lib.ncsu.edu/projects/dataspace-survey-tiny-cafe 